\title{
NuAR - Ambiente Multidisciplinar de Ensino Interativo para a Aprendizagem Criativa
}

\author{
Cláudia Santos Fernandes ${ }^{1}$, Marta Luzzi ${ }^{1}$, Alice Barbosa do Couto ${ }^{2}$, Amanda \\ Raynara Quintana Theodoro ${ }^{1}$, Gustavo Redua de Oliveira ${ }^{1}$, Kryslla Barbosa \\ Rocha de Carvalho', Matheus Nathan de Araujo Martinez ${ }^{2}$, Rodrigo Costa Silva \\ de Oliveira ${ }^{1}$ \\ ${ }^{1}$ Coordenação do Eixo de Informação e Comunicação - Instituto Federal de Educação, \\ Ciência e Tecnologia de Mato Grosso do Sul (IFMS) \\ 79.100-510 - Campo Grande - MS - Brazil \\ ${ }^{2}$ Coordenação do Curso Integrado em Eletrotécnica - Instituto Federal de Educação, \\ Ciência e Tecnologia de Mato Grosso do Sul (IFMS) \\ 79.100-510 - Campo Grande - MS - Brazil

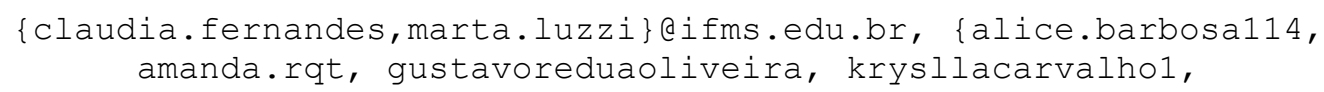

\begin{abstract}
The Animation and Script Center of the IFMS Campus Campo Grande - NuAR seeks to foster reading and writing through bibliographical research and case studies in which students identify topics of social and scientific relevance that are consistent with elements of regional literature and culture. In NuAR, scripts are created using text production techniques, animation techniques are researched, and films are produced. The animations produced are subject to the acceptance of the student's audience. The applied method allows students of the IFMS to multiply knowledge acquired in the workshops of production texts, drawing and animation.
\end{abstract}

Resumo. O Núcleo de Animação e Roteiro do IFMS Campus Campo GrandeNuAR busca fomentar a leitura e escrita, via pesquisas bibliográficas e estudos de caso nos quais os estudantes identifiquem temas com relevância social e científica consoantes com elementos da cultura e literatura regional. No NuAR elaboram-se roteiros a partir de técnicas de produção de texto, pesquisam-se técnicas de animação e produzem-se filmes. As animações produzidas são submetidas à aceitação do público discente. O método aplicado permite aos estudantes do IFMS a multiplicação de conhecimentos adquiridos nas oficinas de produção textos, desenho e de animação.

\section{Introdução}

O Núcleo de Animação e Roteiro do IFMS - NuAR trabalha em prol da leitura e escrita, através do desenvolvimento de pesquisas bibliográficas e estudos de caso que permitam aos estudantes identificarem temas com relevância social e científica consoantes com elementos da cultura e literatura regional. Os trabalhos desenvolvidos vão ao encontro dos objetivos do Instituto de formação interdisciplinar, contextualizada, ativa, objetivos estes, que extrapolam o espaço escolar. 
VIII Congresso Brasileiro de Informática na Educação (CBIE 2019)

Anais do XXV Workshop de Informática na Escola (WIE 2019)

Barros (2016) afirma que "A criatividade na escrita é habilidade fundamental para todo estudante, seja para elaboração de seus diversos trabalhos ou até mesmo para produções de pesquisa acadêmica". Isto posto, tem-se as ações do NuAR como promotoras da formação de senso crítico, concebendo possibilidades de análise que extrapolam o senso comum. Consequentemente, as curtas-metragens de animação contribuem para a formação crítica dos espectadores, visto que as produções se postulam como um olhar outro acerca dos problemas que permeiam o contexto social dos estudantes, uma visada não convencional que convida à reflexão e análise crítica da realidade em que estão inseridos.

Do rol de atividades desenvolvidas, a animação integra-se ao proposto pelos Projetos Pedagógicos dos Cursos Técnicos Integrado, pois abarca o uso de aplicativos, técnicas e conceitos da área de informática, relacionando-se com o uso de técnicas e de conteúdos da área e somando conhecimentos outros aos conteúdos tratados nas unidades curriculares. A produção de roteiros exige o aporte de conhecimentos do campo da literatura e da língua portuguesa, dos estudos de gêneros textuais, dos usos da norma culta e variedades do idioma, fomentando o desenvolvimento da habilidade de produção e de revisão de textos. O campo das artes desenvolve híbridos saberes para o trato com os equipamentos, auxiliando na integração e a inter-relação de múltiplas áreas de conhecimento.

Diante da riqueza cultural de Campo Grande-MS, notada em seus costumes, comidas, músicas e artes, os estudos do NuAR favorecem abordagem criativa das características culturais da cidade, com a inserção dos jovens discentes ao universo da pesquisa e produção de conhecimentos científicos, possibilitando novas leituras e roupagens ao seu mundo, sua cidade, seu bairro, seu espaço, seu ser. Uma vez que os roteiros e histórias são elaborados a partir de temas indicados pelos estudantes, as atividades exigem desenvolvimento de habilidades e conhecimentos múltiplos: elaboração de anotações, relatórios e domínio do vocabulário técnico específico da linguagem cinematográfica.

Isto posto, justifica-se a relevância deste trabalho, visto que as ações apresentadas se integram plenamente aos objetivos do IFMS e seu Plano de Desenvolvimento da Instituição - PDI de promoção de atividades que proporcionem reflexão, formação cultural e política em ações que ultrapassem o âmbito do espaço escolar. A extensão se faz presente pelo oferecimento de oficinas a participantes externos demandados de outras escolas e interdisciplinaridade intrínseca a natureza das ações desenvolvidas.

Este trabalho organiza-se em: Seção 2 - apresenta fundamentos teóricos utilizados na justificativa e orientação dos trabalhos laborados pelo NuAR; Seção 3 - traz metodologia utilizada na condução das atividades do Núcleo e perfila as ações de desenvolvimento; Seção 4 - elucida recorte de resultados obtidos e discussões pertinentes; Seção 5 - tece conclusões ante o exposto e referencia rumos futuros para o $\mathrm{NuAR}$ como ambiente multidisciplinar de ensino interativo para a aprendizagem criativa.

\section{Fundamentos}

Estudos acerca do ambiente de ensino buscam proporcionar e debater as possibilidades de aprofundamento de conteúdos e as dinâmicas de aprendizagem. Incentivos ao ambiente multidisciplinar favorecem o aprendizado discente e ao docente compete o 
VIII Congresso Brasileiro de Informática na Educação (CBIE 2019)

Anais do XXV Workshop de Informática na Escola (WIE 2019)

desenvolvimento não de uma única capacidade, mas variadas formas de pensar em campos diferentes [VIGOTSKII; LURIA; LEONITIEV, 2010, p. 108].

Marcuschi (2004) debate os gêneros textuais emergentes das tecnologias digitais e ambientes virtuais e sua importância na estrutura comunicativa da sociedade, atuando como formas sociais de organização e expressão da vida cultural. Assim, parte-se ao uso das tecnologias numa perspectiva menos tecnicista e mais sócio-histórica. Esta perspectiva mais sócio-histórica perpassa as múltiplas facetas que o aprendiz encontra na leitura em sala de aula. Acerca disso, Geraldi (2017), levando em consideração os campos do léxico, do enunciado, do texto e do contexto, argumenta que a construção de significados, as mudanças de significados e atribuição de sentidos partem sempre do texto, elas são trabalhos de leitura e constroem possibilidades e significações. Deste modo, a leitura que o estudante faz de seu universo e reconta em suas produções audiovisuais subverte o instaurado comportamento social desapegado de leitura nos alémmuro da academia, uma vez que as apresentações dos curta-metragem produzidos propiciam aos expectadores novas leituras e reflexões advindas de seu papel de espectador.

Koch \& Elias (2011) afirmam que a leitura é um processo de construção de significados, isto é, ao ler um texto, seja verbal, seja não verbal, o leitor aciona os conhecimentos armazenados em sua memória, sua bagagem cultural, para atribuir sentido aos elementos que compõem a mensagem. Assim, durante a produção do texto, o autor intencionalmente omite grande quantidade de informações, pois pressupõe que tais saberes são compartilhados entre ele e o leitor, sendo, portanto, desnecessária a menção dessas informações no corpo do texto.

As produções dos estudantes têm início com a elaboração de roteiro. A palavra roteiro deriva de rota e enquadra-se perfeitamente à finalidade do gênero textual que designa, sendo um tipo de texto empregado em várias situações com o fim de orientar a produção de outra obra. Na produção cinematográfica, o roteiro “[...] é um documento escrito que desenvolve uma história e indica como deve realizar-se uma obra para um meio que transmite mensagens através de som e imagem, como o cinema e a televisão" [SOUZA, 2012, p. 1], ou seja, é a versão escrita de uma obra audiovisual. Sua duração é efêmera, pois sua realização se dá no filme, e sua leitura destina-se apenas aos envolvidos na produção da obra audiovisual, como diretores e técnicos de filmagem e de edição, e financiadores do projeto.

O cinema, como indústria "[...] precisa de meios de produção, acumulação de capital e divisão especializada do trabalho. E é a serviço desta indústria, que o roteiro exerce sua principal função" [SOUZA, 2012, p. 1]. O roteiro possibilita noções acerca da extensão da obra audiovisual, das locações, dos materiais e equipamentos necessários $\mathrm{O}$ roteiro também auxilia na previsão de gastos com equipamentos, com mão de obra e proporciona economia de tempo durante a produção audiovisual.

A produção de roteiros padronizados evita desgaste mental e desperdício de tempo, pois a familiaridade com as convenções adotadas no texto permite rápida identificação do assunto. Para atender a essa necessidade de padronização, Moss (1998) sugere a adoção do formato Master Scenes, por ser vantajoso aos iniciantes pela simplicidade, com regras de formatação abrangendo aspectos relativos ao layout (fonte, tamanho do papel, numeração, margens e justificação), com configuração das margens e da justificação variando de acordo com o elemento do roteiro a que se refere. 
VIII Congresso Brasileiro de Informática na Educação (CBIE 2019)

Anais do XXV Workshop de Informática na Escola (WIE 2019)

Convenções e termos técnicos são adotados para designar, de modo conciso e claro, procedimentos relativos à filmagem, ao andamento da ação e à composição das cenas. Além disso, há disponibilidade de softwares livres para a formatação dos roteiros neste padrão, além de ser um dos mais utilizado pela indústria cinematográfica.

O leitor exerce um papel ativo na leitura ao acionar seu conhecimento de mundo para preencher as lacunas deixadas pelo autor. Transpondo esse conceito para o texto fílmico, que é uma mensagem composta por elementos verbais e não verbais, torna-se desnecessário mencionar no corpo do roteiro, por exemplo, que em um restaurante há várias mesas dispostas em um salão e que garçons aproximam-se destas para anotar o pedido dos clientes, pois a leitura da palavra "restaurante" já desencadearia na memória do leitor um modelo socialmente construído de o que é um restaurante. Neste sentido, as convenções do formato Master Scenes possibilitam a omissão, no roteiro, de informações que deverão ser apreendidas visualmente pelos espectadores. Em "Denise se levanta do sofá e vai para a ... / COZINHA, onde abre a geladeira e pega uma cerveja" [MOSS, 1998, p. 6], a grafia em caixa alta da palavra "cozinha" indica que a imagem deve descrever esse ambiente. Tal artifício também se aplica a detalhes importantes da cena como sons e pormenores de imagem, indicando que estes devem ser destacados, para indicar a primeira vez que um personagem aparece no filme ou na cena, além das indicações "ENTRA e SAI" para indicar entrada e saída de cena.

Um dos objetivos da sujeição às regras da formatação é fazer com que o roteirista se dedique à construção do enredo do filme, deixando os detalhes técnicos e a composição de imagens para a direção. Outro objetivo da formatação é evitar a inclusão de fatos invisíveis no texto do roteiro. Na descrição literária, é muito comum o narrador investigar o estado psicológico dos personagens, descreem-lhes os sentimentos e intenções. Na composição do roteiro, no entanto, deve-se ter o cuidado de incluir no texto somente as informações que o espectador pode perceber visualmente. O Master Scenes " [...] ajuda a evitar um outro erro comum nos roteiros [...]: o de incluir fatos invisíveis nos textos de descrição" [MOSS, 1998, p. 2].

A produção dos desenhos e, depois, das animações tem como ponto de partida a elaboração de storyboards que segundo Morais (2015) "[...] possuem um processo de criação simplificado, facilitando e tornando ágil a comunicação e transmissão de informações, tanto no processo, com a documentação do projeto para a equipe, quanto na interface com o usuário" [p. 530]. Dessa forma, são elaboradas uma série de ilustrações organizadas em sequência com o objetivo de facilitar a confecção e visualizar previamente as animações.

Quanto a técnica de desenhos, elencou-se a técnica de mangás, que, de acordo com a editora JBC (2011), designa as histórias em quadrinhos no estilo japonês, tendo como principais características os olhos grandes e expressivos dos personagens, responsáveis pela demonstração de suas emoções, e são embasados por roteiros dinâmicos e de rápida leitura, que prezam mais o movimento e a ação. Caracterizam-se por uma estrutura simples do corpo humano, semelhante à técnica de desenho convencional, com proporções e características de esboço com corpo humano, medidas e ângulos que tomam por medida a cabeça, pescoço e ombros semelhantes aos quadris e membros, sendo estes demarcados pelas articulações do corpo comum a qualquer técnica de desenho. 
Embora seja semelhante ao desenho artístico tradicional, o mangá se destaca pelo exagero das expressões do rosto, dando extremo valor aos olhos e quase nenhum valor ao nariz e a boca, sendo estes meros complementos ao rosto do personagem. Em alguns personagens, até mesmo a ausência do nariz e/ou das orelhas são notados, ocultados pelo cabelo. Traços específicos do mangá, convencionados para demarcação de emoções como alegria, tristeza, meditação, nervosismo, raiva, determinação ou medo são essenciais para aplicação deste método de desenho.

Quanto a técnica de filmagem, optou-se pela filmagem quadro a quadro que, de acordo com Wiedemann (2009) e Williams (2008), consistem na coleção de diversas fotos dos quadros representativos contendo poucas modificações de maneira a criar, através da apresentação das figuras, uma única imagem em movimento. Esta técnica tem como principal precursora a técnica do stop motion, ou frame by frame. Segundo Ciriaco (2011), o stop motion, expressão que pode ser traduzida como "move e para", é uma técnica que utiliza a disposição sequencial de diversas fotos diferentes de um mesmo objeto inanimado para simular o seu movimento. Estas fotografias são chamadas de quadros e normalmente são tiradas de um mesmo ponto, com o objeto sofrendo uma leve mudança de lugar, dando a ideia de movimento.

\section{Metodologia e Desenvolvimento}

As atividades deste projeto se deram em 3 fases concomitantes, conforme segue: I) Estruturação do núcleo para capacitação de estudantes do IFMS do Campus Campo Grande de diferentes cursos e níveis; II) Produção de roteiros, storyboards e animações; III) Multiplicação de conhecimento por oferecimento de oficinas a outros estudantes do IFMS e de outras escolas do município.

No Núcleo de Roteiros, foram seguidas as seguintes etapas de desenvolvimento: pesquisa bibliográfica, oficinas e palestras abordando elementos da cultura e literatura local, estudo de técnicas de desenho e de produção de textos e roteiros de forma colaborativa. No Núcleo de Animação, as atividades desenvolvidas foram: estudos das principais técnicas de animação, dos princípios de animação gráfica e dos softwares livres disponíveis para esse fim. Os roteiros passaram por análise a fim de determinar-se as técnicas de animação a serem utilizadas. Partiu-se então a produção de curtas metragens e posterior análise/seleção feita pelos participantes do NuAR seguindo-se à apresentação aos demais estudantes do IFMS Campus Campo Grande.

No quesito de filmagem a técnica elencada foi a de quadro a quadro, baseada no stop motion (ou frame by frame) e possíveis aplicações de técnicas para produção dos movimentos. Como suporte tecnológico, optou-se pelos softwares para produção digital das animações Alice, Blender, Scratch e Windows Live Movie Maker. As técnicas de programação exploradas foram as da linguagem Java Script.

Todas estas etapas foram supervisionadas e continuamente avaliadas pela equipe do NuAR e convidados atuantes em áreas, promovendo análise do aprendizado dos conteúdos, dos roteiros, storyboards e animações produzidas.

Como etapa final, os estudantes são inseridos no universo da propriedade intelectual, debatendo-se a proteção de suas animações. 
VIII Congresso Brasileiro de Informática na Educação (CBIE 2019)

Anais do XXV Workshop de Informática na Escola (WIE 2019)

\section{Resultados e Discussão}

Os resultados colhidos no desenvolvimento do projeto, até o momento, consistiram em: a) participação em reuniões e debates com os integrantes do grupo; b) promoção de estudos dirigidos sobre textos de autores nacionais/regionais; c) visita à Biblioteca "Isaías Paim"; d) participação de oficina sobre o autor "Manoel de Barros"; e) estudo de técnicas de animação; f) estudos e seleção de Softwares e linguagens para animações, vídeos e músicas, por fim, e) oficina de áudio descrição.

Os participantes do NuAR também atuaram como ministrantes de oficinas nas Semanas de Ciência e Tecnologia do IFMS 2017 e 2018: a) oficina "Introdução ao Blender", contemplando introdução à ferramenta, estudo da área 3D, comandos de navegação, introdução à modelagem, lighting, renderização e texturização; b) oficina "Ensino de Lógica de Programação por meio do Software de Animação 3D Alice"; c) oficina "A arte de criar e animar no papel", buscando o ensino de noções básicas de desenho e animação, além discussões acerca da presença de animações no cinema. Esta oficina também tratou das questões da criatividade no labor do desenho e formas de despertá-la e maximizá-la, utilizando-se "métodos tradicionais" de desenho, com papel, lápis e borracha e ocorreu em dois dias. Os tópicos tratados foram: animação, surgimento da animação, etapas de produção de uma animação (atuais e antigas), desenho, elementos básicos da comunicação visual, aquecimento, esboço, proporções, cores, sombra e profundidade, criatividade, definição da criatividade, tipos de criatividade, potencial criativo, processo criativo, formas de expressão, como ampliar a criatividade.

Ressalta-se que, em paralelo ao aprendizado e uso do software, as oficinas também promovem a análise de textos literários de autores nacionais e regionais, como Manoel de Barros, compondo a criação de pequenos roteiros escritos e ilustrados pelos alunos, projetados em animações no software Alice.

Os participantes do NuAR também participaram de oficinas durante a "Semana do Meio Ambiente" e "Semana de Ciência e Tecnologia", ambas no Campus Campo Grande-MS, e apresentação do projeto na "Feira de Ciência e Tecnologia do Campus Campo Grande - FECINTEC 2018" com o oferecimento da oficina "Animação 3D e Lógica de Programação utilizando o Software Alice" e em paralelo a exposição do banner. No mesmo ano, o grupo também se fez presente em outros dois eventos: "Computer On The Beach - 2018" e "ConectaIF - 2018".

Quanto as apresentações de trabalhos na "Semana de Ciência e Tecnologia", "Feira de Ciência e Tecnologia do Campus Campo Grande - FECINTEC 2018", Feira de Tecnologias, Engenharias e Ciências de Mato Grosso do Sul - FETEC 2018 foram colhidas boas avaliações e premiações, com excelente pontuação, além de feedback positivo. Em relação as apresentações no "Computer On The Beach - 2018" e "ConectaIF - 2018", estes resultaram em publicações de artigo completo e resumo expandido, respectivamente. Por fim, no segundo semestre de 2018, o projeto foi contemplado com a aprovação de novas 3 bolsas de Iniciação Científica para o ciclo 2018-2019, promovendo novo fôlego à empreitada, e propiciando desenvolvimento das ações continuadas de ensino, pesquisa e extensão.

Das atividades realizadas, colheram-se frutos de importante valor ao ensino/aprendizagem dos educandos. As seguintes técnicas de animação foram contempladas: a) animação tradicional, com os quadros elaborados um a um, por meio de 
VIII Congresso Brasileiro de Informática na Educação (CBIE 2019)

Anais do XXV Workshop de Informática na Escola (WIE 2019)

desenhos ou retratados com objetos inanimados, seguido da organização dos quadros de forma a criar a ilusão de animação utilizando-se software específico, ou uma filmagem utilizando a técnica "Draw my life" em que histórias são contadas por meio da filmagem de diversos desenhos sequenciais, ou simplesmente um flipbook (Figura 1);

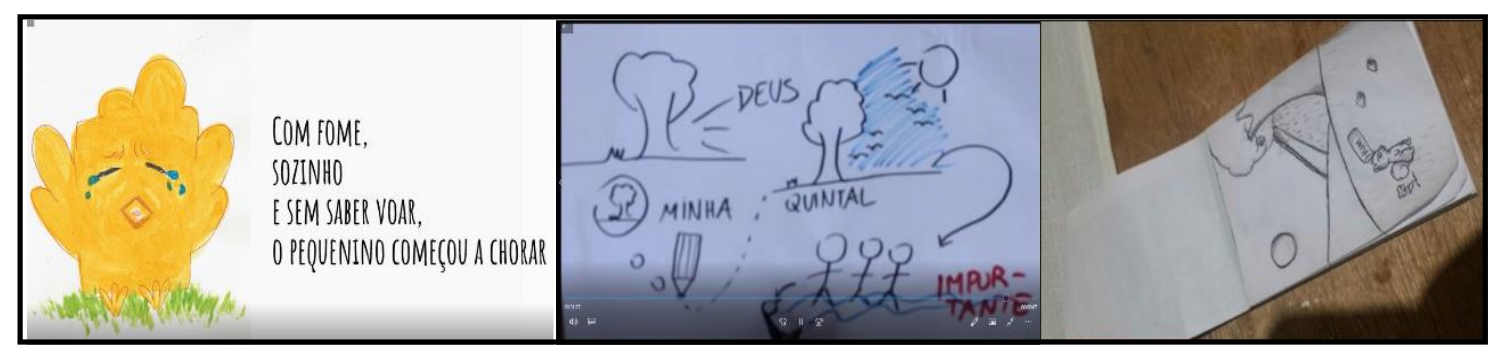

Figura 1. Respectivamente, Voar como um pássaro" vídeo desenvolvido utilizando o software "Power Point; O Lápis" de "Manoel de Barros" - Animação produzida utilizando a técnica do "Draw my life" e Flipbook produzido pelos participantes.

b) animação digital, que contemplas as animações criadas pelo uso computadores, podendo ser elaboradas com imagens gráficas em 2 ou 3 dimensões, utilizando-se softwares livres, com ambiente gráfico interativo, tais como o Adobe Flash, Pencil, Blender (Figura 2), Alice, entre outros, como também a linguagem de programação Java Script. Ressalta-se que a presença dos textos literários para a composição de roteiros favorece a junção das áreas, promovendo a informática e a língua portuguesa e tornando as atividades de pesquisa e aprimoramento prazerosas.

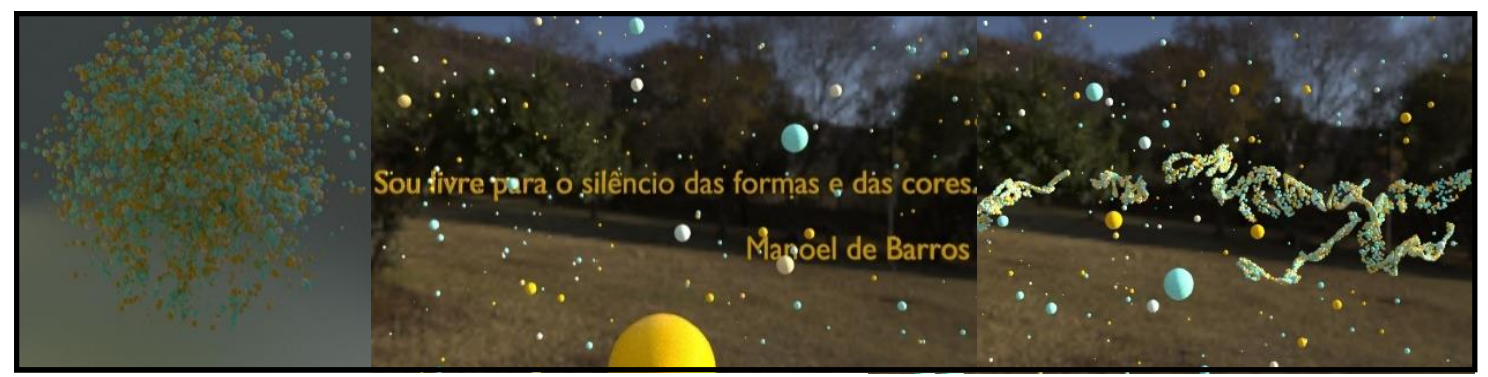

Figura 2. Sequência da animação produzida com a frase de Manoel de Barros "Sou livre para o silêncio das formas e da cores" utilizando o software Blender.

O NuAR segmenta-se em 3 grupos intitulados "Jaguars", "Zoinho" e "Melbourne", que trabalham com animações distintas. O "Jaguars" pesqu isou, estudou e selecionou tema, elaborando história, roteiro técnico e personagens sob técnica de animação 2D, com uso de mesa digitalizadora e software para produção da animação quadro a quadro, concentrando-se nos storyboards e cenários (Figura 3).

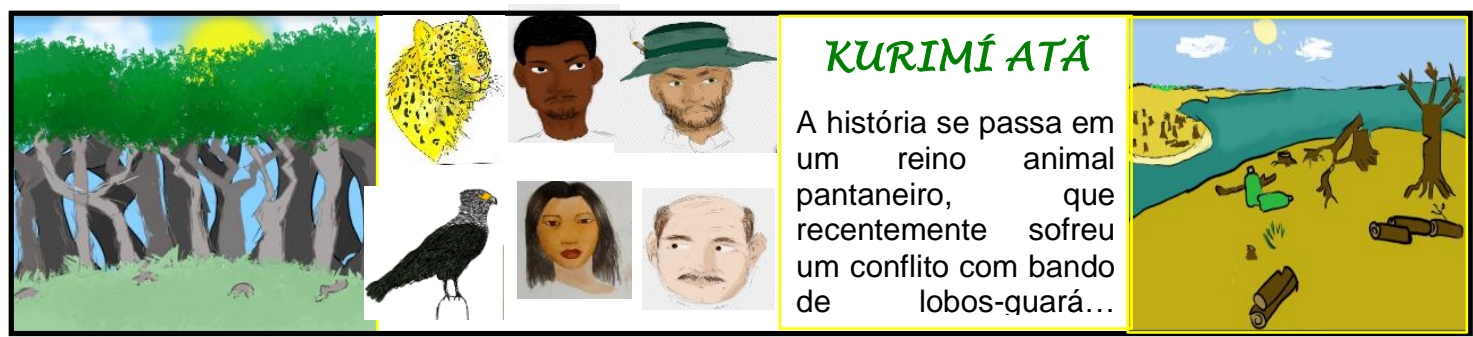

Figura 3. Parte do roteiro técnico, personagens e cenários produzidos pelo grupo Jaguars. 
VIII Congresso Brasileiro de Informática na Educação (CBIE 2019)

Anais do XXV Workshop de Informática na Escola (WIE 2019)

O grupo "Zoinho" desenvolveu uma mascote (Figura 4) em que é utilizada a técnica de animação em 3D denominada de skinning que de acordo com Campos (2004, p. 46) consiste em "[...] anexar uma pele (skin) ao esqueleto do personagem e movimentar essa pele de acordo com a posição dos ossos do esqueleto. A pele consiste em um conjunto de vértices que dão forma ao personagem possuindo determinadas texturas". Os participantes deste grupo, também estudaram textos, elaboraram roteiros, construíram cenários e elegeram o software Blender para a elaboração de sua animação (Figura 4).

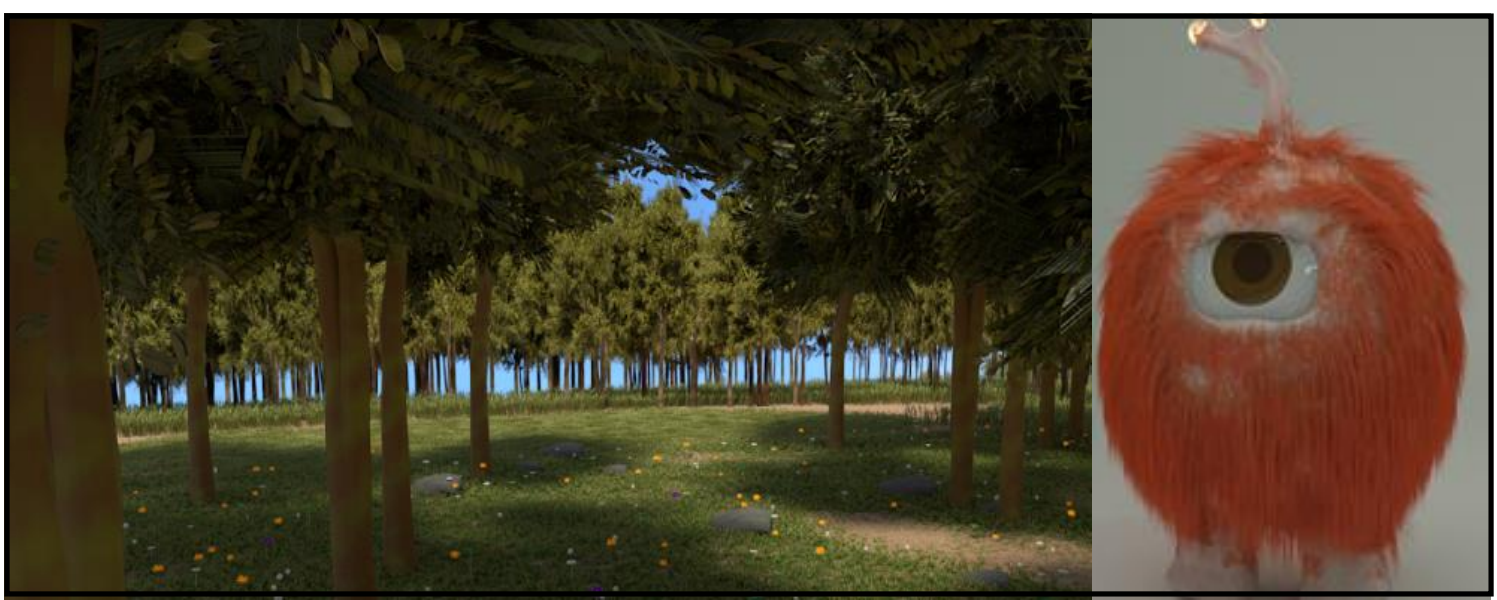

Figura 4. Cenário e mascote, produzido pelo grupo Zoinho, respectivamente.

O grupo "Melbourne" desenvolveu um roteiro de suspense denominado "Quem Matou Annie Hawking", inspirado em algumas obras clássicas como "Os sofrimentos do jovem Werther" de Johann Wolfgang vonGoethe, "Romeu e Julieta" de William Shakespeare e "Desventuras em série" de Daniel Handler. O grupo optou pela animação 2D utilizando de mesa digitalizadora e software Opentoonz, elaborando o roteiro técnico, cenários, objetos e personagens: na figura 5 podem ser observado essas criações, com também o processo criativo do grupo.

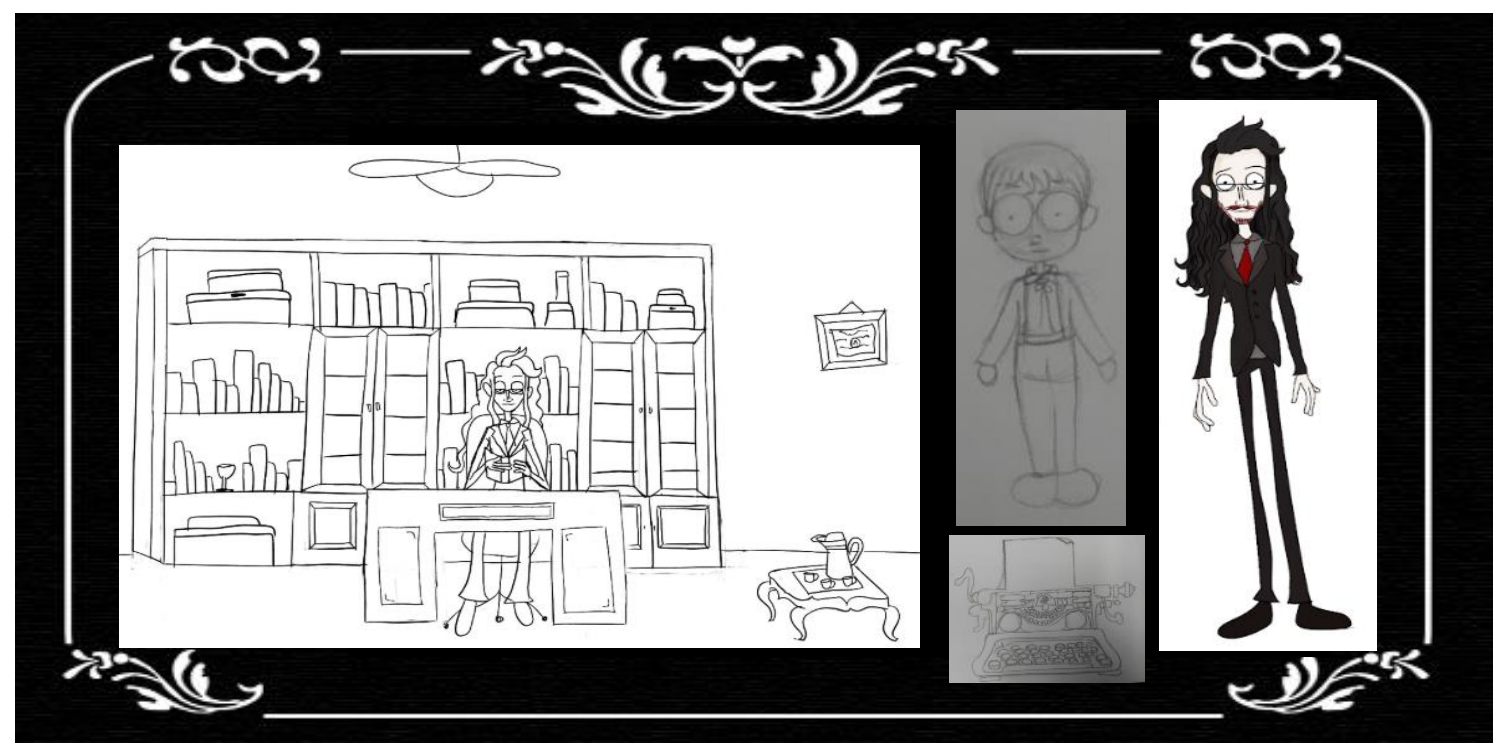

Figura 5: Cenário, objetos e personagens criados para a animação da equipe "Melbourne". 
VIII Congresso Brasileiro de Informática na Educação (CBIE 2019)

Anais do XXV Workshop de Informática na Escola (WIE 2019)

Para o quesito das trilhas sonoras e músicas, o NuAR conta com atuação de seus membros músicos que laboram para a composição temas a serem utilizados em suas produções.

\section{Conclusões e Trabalhos Futuros}

O projeto aqui posto pretende oferecer oportunidades de aprendizagem efetiva aos jovens, ampliando a visão de comunidade, de mundo e da sua capacidade de transformálo. O NuAR advoga para que o interesse pela comunicação, tecnologia, arte e literatura local seja desperto e investe no ramo de produção de roteiros para animação.

As curtas-metragens de animação elevam o nível processual do ensino/aprendizagem, promovendo o interesse pela leitura, desenvolvendo a criatividade e levando os espectadores à reflexão, a análise crítica da realidade em que a comunidade se insere. Por esta razão a elaboração proposta comunga com os objetivos do IFMS de formação interdisciplinar, contextualizada, ativa e crítica de seus estudantes, tornando-os agentes capazes de transformar a sociedade - objetivos que extrapolam o espaço escolar.

A animação está intrinsecamente ligada aos Projetos Pedagógicos dos Cursos Técnicos Integrado, pois propõe o uso de aplicativos, técnicas e conceitos das áreas de Língua Portuguesa, Literatura, Artes, Desenho Técnico e Informática. A extensão está integrada à ação, pelo oferecimento de oficinas a participantes externos demandados de outras escolas e a interdisciplinaridade está intrínseca a natureza das ações propostas. A produção de roteiros exige aporte de conhecimentos no campo da língua portuguesa, do estudo de gêneros, dos usos da norma culta e as variedades distensas do idioma, além do desenvolvimento da habilidade de produção e de revisão de textos. Quanto ao campo da informática aplicada, utilizam-se conhecimentos específicos dos aplicativos de formatação dos roteiros, edição de vídeos e criação das animações. Por fim, na área das artes, aplicam-se técnicas de desenho e a criação de personagens, com o desenvolvimento de variados saberes para manuseio dos equipamentos, levando a composição formal de cada personagem criado em seus roteiros. Tais interações auxiliam a integração e a interrelação dos conhecimentos das variadas áreas implicadas no trabalho.

Conclui-se que as ações das atividades abarcam a interdisciplinaridade, o desenvolvimento de senso crítico e do interesse por temas de relevância social, a valorização da cultura e literatura local, a inserção dos estudantes no universo da produção de conhecimentos científicos e a democratização dos saberes.

Nesse sentido, é importante ressaltar que houve uma percepção positiva quanto ao interesse dos estudantes aos temas desenvolvidos neste projeto, visto que o NuAR contava inicialmente com 3 estudantes e, atualmente, são 23, corroborando com o interesse pela comunicação, pela tecnologia e a pela língua portuguesa no viés da leitura e da escrita.

Assim, o NuAR busca continuar o seu caminhar, vislumbrando o futuro de prazeroso processo de ensino/aprendizagem, tendo como próximas etapas estudos de outras técnicas de animação, elaboração roteiros, confecção de storyboards, visitas técnicas a bibliotecas e a ambientes culturais, seleção de roteiros para animação e oferta de oficinas de elaboração de roteiros e técnicas de animação a estudantes para o além muro do IFMS. 
VIII Congresso Brasileiro de Informática na Educação (CBIE 2019)

Anais do XXV Workshop de Informática na Escola (WIE 2019)

\section{Agradecimentos}

Apoiaram este trabalho: Instituto Federal de Mato Grosso do Sul (Edital - 028/2019 Propi/IFMS - Iniciação Científica e Tecnológica), Ministério da Cultura - Núcleo de Produção Digital (NPD)/IFMS Campus Campo Grande.

\section{Referências}

Barros, E. C. e Menezes, C. S. (2016) "EsCola - Ambiente Educacional para Escrita Colaborativa", In: Anais, XXVII Simpósio Brasileiro de Informática na Educação SBIE, Uberlândia, p. 1265-1264.

Campos, M. B., Maiocchi, D. e Bortolin, M. (2004) "SIGNHQ: sistema de autoria para criação e leitura de Histórias em Quadrinhos com suporte à Língua de Sinais", In: Anais do XV Simpósio Brasileiro de Informática na Educação (SBIE), Manaus, p. 4446.

Ciriaco, D. (2011) “O que é Stop Motion?”, http://www.tecmundo.com.br/2247-o-que-estop-motion-.htm, junho.

JBC. (2011) “O que é Mangá”, http://mangasjbc.com.br/o-que-e-manga/.

Koch, I. V. e Elias, V. M. (2011) Ler e compreender: os sentidos do texto, Contexto, $3^{\text {a }}$ edição.

Marcuschi, L. A. (2004) “Gêneros textuais emergentes no contexto da tecnologia digital”, In: Hipertexto e gêneros digitais, Organizado por Marcuschi, L. A. and Xavier, A. C., Editora Lucerna, Rio de Janeiro.

Morais, D. C. S, Gomes, T. C. S., Souza, A. F. B. e Peres, F. M. A. (2015) "Storyboards no Desenvolvimento de Jogos Digitais Educacionais por Usuários Finais: Um Relato de Experiência”, In: Anais do XXVI Simpósio Brasileiro de Informática na Educação (SBIE), Maceió, p. 529-538.

Moss, H. (1998) "Como formatar seu roteiro", http://www.roteirodecinema.com.br/manuais.htm.

Souza, F. (2015) "Roteiro de cinema: um documento chamado roteiro", http://www.roteirodecinema.com.br/manuais/documentochamadoroteiro.htm.

Vigotskii, L. S, Luria, A. R. e Leonitiev, A. N. (2010) Linguagem, desenvolvimento e aprendizagem, Cone Editora, $11^{\mathrm{a}}$ edição.

Wiedemann, J. (2009) Animation now!, Taschen Br, $1^{\text {a }}$ edição.

Williams, R. (2008) TheAnimator's survival kit: a manual of methods, principles and formulas, Farrar Straus \& Giro, $1^{\text {a }}$ edição. 